\title{
Application of unilateral external fixation by the "joystick technique" in the treatment of pediatric tibia shaft fractures: technical note
}

\author{
Xinhui Wang ${ }^{1 \dagger}$, Zhe Zhang ${ }^{2 \dagger}$, Xizhi Hou ${ }^{3}$, Bao Wang ${ }^{1}$, Yongdong $\mathrm{Li}^{1}$ and Tao Zhang ${ }^{1 *}$
}

\begin{abstract}
Background: The aims of current study were to present the clinical outcomes in patients with pediatric tibia shaft fractures who were treated with unilateral external fixation combined with joystick for fracture reduction and describe the details of our technique.

Methods: We retrospectively analyzed the patients with pediatric tibia shaft fractures who were treated with unilateral external fixation combined with joystick for fracture reduction between July 2018 and March 2020. The clinical outcomes were evaluated.

Results: A total of 23 patients were included in the current study with the average age of 8.0 years (ranged 4-14 years). The average duration of hospital and follow-up were 5.9 days (ranged 4-8 days) and 17.4 months (ranged 8-27 months), respectively. At postoperative 3 days, the visual analog scale (VAS) score was $3.1 \pm 1.43$, which was significantly lower than the preoperative score of $7.3 \pm 1.5$. Of these, 2 cases showed redness and swelling of pin-tract and exudation at postoperative 1 month, who improved after oral antibiotics without causing fixation failure. The average time to full weight-bearing without crutches was 5.1 weeks (ranged 3-8 weeks). All patients achieved fracture healing and good functional recovery. No complications including fixation failure, reoperation, epiphyseal injury occurred, infection around implants, vessel damage, nerve damage, and limitation of joint movement were observed. The Johner-Wruh scores showed that 21 cases (91.3\%) were "excellent" and 2 cases (8.7\%) were "good."

Conclusions: This procedure had advantages of simple operation, minimum trauma, early recovery of lower limb function, and no risk of complications. It may provide a new choice for children with tibia shaft fractures who require surgical treatment.
\end{abstract}

Keywords: Pediatric tibia shaft fracture, Unilateral external fixation, Joystick technique

\section{Background}

Tibia fracture is a common injury in children accounting for $15 \%$ of children's fractures, and $40 \%$ of tibia fractures are located in the middle of the tibia [1-3]. Since

\footnotetext{
*Correspondence: zhangtaopc50500@163.com

'Xinhui Wang and Zhe Zhang equally contributed to this paper and thus shared the co-first authorship.

1 Emergency, Trauma Center, The Third Hospital of Hebei Medical

University, No.139 Ziqiang Road of Qiao'xi District, Shijiazhuang 050000, Hebei, China

Full list of author information is available at the end of the article
}

pediatric fractures with characteristics of faster healing and strong shaping ability, cast external fixation was treated for was tibia shaft fractures with insignificant displacement, which achieved satisfactory outcomes, especially for greenstick fractures [4]. However, for significantly displaced tibia fractures, surgical treatment should be considered to avoid sequelae caused by shortening, rotation, or severe force line changes. Recently, the surgical approaches for treating tibia shift fractures include external fixation, titanium elastic nail (TEN), and open reduction and internal fixation [5-7]. Despite the 
development of these surgery methods, open reduction and internal fixation has several disadvantages including large trauma, destruction of blood supply, and increases the risk of bone nonunion and infection $[5,8]$. At the same time, the inevitable surgery to remove internal fixation will cause secondary injury to the child. Therefore, the minimally invasive surgical treatment of pediatric tibia shaft fractures is urgent.

TEN has been first reported in 1988 by Ligier et al. [9], which was quickly accepted and promoted for use in pediatric tibia shaft fractures. Previous studies have demonstrated that TEN is beneficial for the treatment of pediatric tibia shaft fractures $[8,10,11]$. In practical application, TEN is most suitable for transverse or short oblique fractures. However, its fixation strength is reduced for other fracture types such as long oblique or spiral fractures, and it needs to be combined with external fixation with a brace, thereby influencing early functional exercise $[8,12]$. Additionally, TEN can cause secondary surgery to remove internal fixation as well [7]. With regard to external fixation, it is deemed as a primary and effective treatment for pediatric tibia shaft fractures despite the complications $[5,13]$. But there are still few studies on the use of external fixation to treat tibia shaft fractures in children, and a mature treatment system has not been formed.

Translational orthopedics is that new orthopedic technique which is efficiently transformed from the scientist to the clinician [14]. In this study, we tried to apply a unilateral external fixator combined with joystick for fracture reduction in the treatment of pediatric tibia shaft fractures. In order to accelerate understanding the clinical application, we described the details of this technique and explored the clinical outcomes.

\section{Methods}

\section{Patients}

Children with tibia shaft fractures who were admitted to the Trauma Emergency Center of the Third Hospital of Hebei Medical University between July 2018 and March 2020 were retrospectively analyzed in this study. Inclusion criteria were patients who (1) were aged from 4 to 14 years, (2) were closed or Gustilo I type tibia shaft fracture, and (3) had obvious displacement or unstable fracture and poor closed reduction. Exclusion criteria were patients who had (1) fractures at other sites, (2) Gustilo II or Gustilo III type tibia shaft open fracture, (3) closed fracture with nerve and blood vessel damage, and (4) other severe disabilities or medical diseases.

\section{Surgery procedure}

External fixation was performed in all patients under general anesthesia. After successful anesthesia, the patient was placed in the supine position on the operating beds. In general, half-pin with a diameter of $4 \mathrm{~mm}$ was used to fix the tibia shaft fractures in children and $5 / 6 \mathrm{~mm}$ diameter for individual patients with larger body weight.

To reduce soft tissue irritation, simple fractures should be fixed with 4 half-pins first. After the fracture was reduced and fixed, if necessary, additional half-pins were added to each fracture segment to increase the fixation strength [15]. The half-pins were fixed in turn at the nearest, farthest, and close to the fracture (Fig. 1A). All 4 half-pins were located on the anterior medial surface of the tibia [2]. In order to increase the holding force of the external fixation frame, the selection of the position of the half-pins followed the "near-near, far-far principle." That is, the most farthest and nearest half-pins should be as far away from the fracture as possible, and the middle half-pins should be as close as possible to the fracture [15] (Fig. 1B).

Especially for patients with older age, another unilateral external fixator was added to the outside. The outside fixator needed 2 half-pins. The proximal end was located below the level of tibia tubercle, and the distal end was driven through the fibula into the tibia. The connecting rod was used to connect the lateral half-pin to increase stability (Fig. 1C).

After inserting the distal and proximal half-pins, traction reduction was performed to restore the tibia rotation and the length of the tibia. The distal and proximal nail caps were tightened to firmly fix the half-pins and connecting rods. The intraoperative $\mathrm{C}$-arm fluoroscopy of the fracture in the anteroposterior and lateral position was used to detect whether the fracture length is restored. On the premise of confirming the length recovery, the dislocation of the fracture was detected.

Since the external fixator is located on the inner side of the tibia, if there was only mediolateral displacement of the fracture but no anteroposterior displacement, two half-pins were inserted into close to the fracture first. Subsequently, according to the displacement, the pressing technique or leverage method was adopted. After pressing or lifting the fracture, satisfactory reduction was obtained by tightening the nail cap (Fig. 2A-D). If there was anteroposterior displacement, inserting a half-pin as joystick into the anterior tibia crest near the fracture was recommended. After closed and reduction of the fracture under fluoroscopy, half-pins were placed on each side of the fracture to fix, and satisfactory reduction was also obtained (Fig. 2E, F).

\section{Postoperative management}

Postoperatively, the affected limb was elevated and intravenous antibiotics were used for $48 \mathrm{~h}$ of anti-infective 


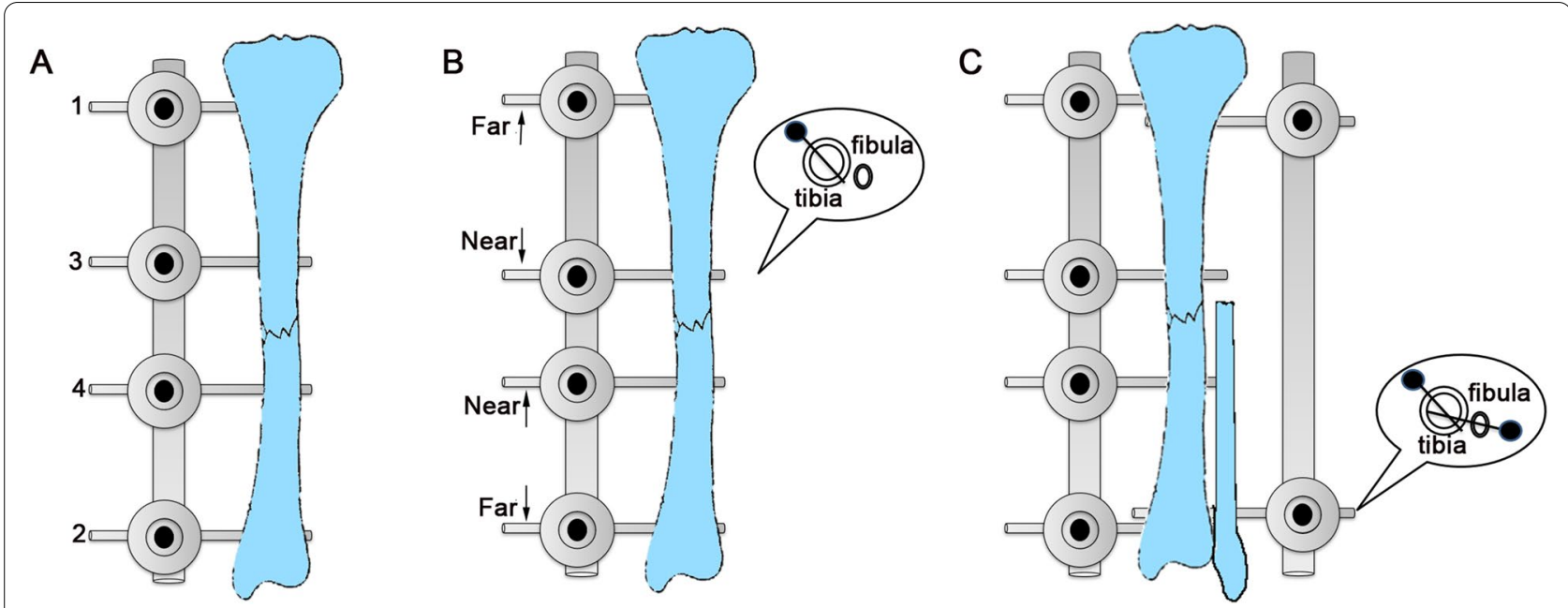

Fig. 1 The fixation skills of pediatric tibia shaft fractures. A The sequence of placement of half-pins in turn at the nearest (1), farthest (2), and close to the fracture $(3,4)$. B The selection of the position followed the "near-near, far-far principle," and 4 half-pins were inserted from the inner surface of the tibia perpendicular to the bone surface. The outside fixator needed 2 half-pins. C The proximal end was located below the level of tibia tubercle, and the distal end was driven through the fibula into the tibia

treatment. On the second day after the operation, the patients were instructed to perform non-weight-bearing exercises of the knee and ankle joints on the premise that the pain was tolerable after the pain subsided. One week after the operation, the patients were instructed to move on crutches after reduction of the swelling of the affected limb. Beginning 2-3 weeks after the operation, the patients were instructed to exercise the weight-bearing function of the affected limb using a weight scale under the protection of crutches.

Bone union was evaluated by the X-ray results of reexamination after surgery according to the previous study [12]. Briefly, when an adequate bridging callus was observed on a radiograph, the patients were instructed to walk with full weight-bearing gradually. When patients can take off the crutches to walk with no pain, we believed that the patient has reached clinical healing. After clinical healing was achieved, half-pins were gradually removed in 2-3 times until they were completely removed. The interval time for each removal of external fixator was about 1 month.

\section{Clinical outcomes}

Visual analog scale (VAS) was to assess the pain at preoperation and postoperative 3 days. During the follow-up, the fracture healing, complications, and functional recovery were recorded. At the last follow-up, the patient's recovery was evaluated according to the Johner-Wruh tibia fracture curative effect evaluation system [16] (Table 1).

\section{Statistical analysis}

Data were analyzed using SPSS 19.0 software (IBM Corp., Chicago IL, USA). The measurement data were compared using $t$ test, while the enumeration data using chi-square test. $P<0.05$ was considered to the statistically significant difference.

\section{Results}

A total of 23 patients were included in the current study with the average age of 8.0 years (ranged $4-14$ years). The average hospital duration and follow-up were 5.9 days (ranged 4-8 days) and 17.4 months (8-27 months), respectively. There were 14 males and 9 females, and there were 12 cases on the left side and 11 cases on the right side. The injury was caused as a result of traffic accidents in 9 cases (39.1\%), sprain in 9 cases (39.1\%), heavy objects in 3 cases $(13.0 \%)$, and other causes in 2 cases (8.7\%) (Table 2).

At postoperative 3 days, the average VAS score of patients was $3.1 \pm 1.43$, which was significantly lower than the preoperative score of $7.3 \pm 1.5$ (Table 3 ). Of these, 2 cases showed redness and swelling of pin-tract and exudation at postoperative 1 month. Fortunately, these conditions were controlled through oral antibiotic treatment and pin tract care. The average time to full weight-bearing without crutches was 5.1 weeks (ranged 3-8 weeks). The maintenance period of the external fixator was 13.5 weeks (ranged 10-17 weeks). All patients achieved fracture healing, and no complications were observed including fixation failure, reoperation, epiphyseal injury occurred, infection 


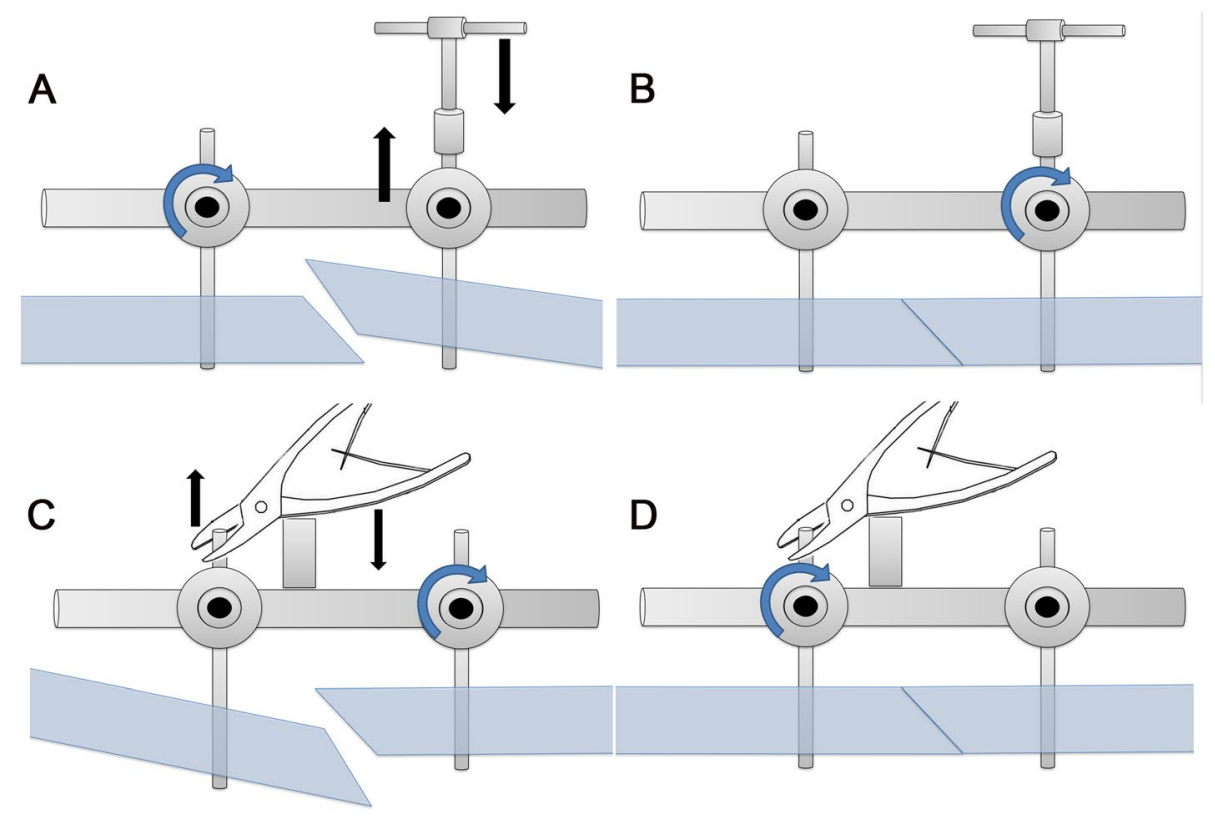

E

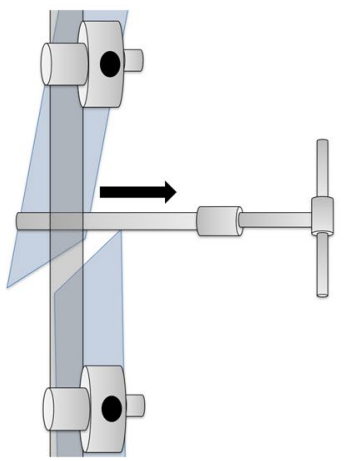

F

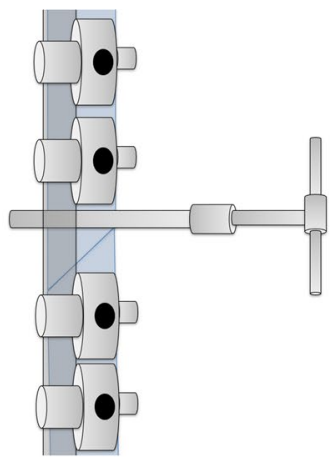

Fig. 2 Application of joystick technique in pediatric tibia shaft fractures. A-D Two half-pins were inserted into close to the fracture, and then the pressing technique or leverage method was adopted according to the displacement. E, F Inserting a half-pin as joystick into the anterior tibia crest near the fracture was used for anteroposterior displacement. After closed and reduction of the fracture, half-pins were placed on each side of the fracture to fix

around implants, vessel damage, nerve damage, and limitation of joint movement (Figs. 3 and 4).

During follow-up of 12 months, the patients showed good functional recovery, and none of them showed obvious unequal length of lower limbs and claudication. The Johner-Wruh scores at the end of 12 months were "excellent" for 21 cases (91.3\%) and "good" for 2 cases (8.7\%). The advantages and limitations of this study were shown in Table 4.

\section{Discussion}

External fixation is a common surgical technique for tibia-fibula fractures, especially for open tibia-fibula fractures. In general, external fixation is utilized as a temporary fixation to restore the length and force of the tibia and fibula, and then changed to internal fixation treatment, which can often achieve satisfactory outcomes $[17,18]$. With the advancements of external fixation technology and equipment, it is deemed as ultimate treatment for tibia-fibula fractures, and even applied to the treatment of closed fractures, which achieves good therapeutic effects $[19,20]$. Combined with the children characteristics of fast healing and strong shaping ability, the external fixation has superiority of small trauma and no secondary surgery, which is deemed as a reasonable treatment option [13, 21]. However, there are still few studies on the use of external fixation to treat tibia shaft fractures in children. A previous study has reported that unilateral 
Table 1 Johner-Wruh scoring system

\begin{tabular}{llll}
\hline & Excellent & Good & Medium \\
\hline Infection/non-healing & No & No & No \\
Neurovascular injury & No & Mild & Moderate \\
Varus and valgus deformities & No & $2^{\circ}-5^{\circ}$ & $6^{\circ}-10^{\circ}$ \\
Anterior and posterior bending deformities & $0^{\circ}-5^{\circ}$ & $6^{\circ}-10^{\circ}$ & $11^{\circ}-20^{\circ}$ \\
Rotation deformity & $0^{\circ}-5^{\circ}$ & $6^{\circ}-10^{\circ}$ & $11^{\circ}-20^{\circ}$ \\
Shortening deformity & $0^{\circ}-5^{\circ}$ & $6^{\circ}-10^{\circ}$ & $11^{\circ}-20^{\circ}$ \\
Knee range of motion & Unlimited & $>80 \%$ & $>75 \%$ \\
Ankle range of motion & Unlimited & $>20^{\circ}$ & $>50 \%$ \\
Pain & No & $>20^{\circ}$ \\
Gait & Normal & Occasional & Moderate \\
Daily activities & Unrestricted & Normal & Mild limp \\
& & Restricted & Severely restricted \\
\hline
\end{tabular}

Table 2 Patient characteristics

\begin{tabular}{|c|c|c|c|c|c|c|c|c|}
\hline Case & Age (years) & Gender & Fracture side & Injury causes & $\begin{array}{l}\text { Duration of } \\
\text { hospital (day) }\end{array}$ & $\begin{array}{l}\text { Weight- } \\
\text { bearing } \\
\text { (day) }\end{array}$ & Complications & Johner-Wruh score \\
\hline 1 & 4 & Male & Left & Heavy objects & 4 & 3 & No & Excellent \\
\hline 2 & 13 & Male & Right & Traffic accident & 8 & 6 & No & Excellent \\
\hline 3 & 5 & Male & Left & Traffic accident & 7 & 4 & No & Excellent \\
\hline 4 & 9 & Male & Left & Heavy objects & 6 & 8 & Pin tract infection & Good \\
\hline 5 & 12 & Male & Right & Sprain & 4 & 5 & No & Excellent \\
\hline 6 & 4 & Male & Left & Traffic accident & 5 & 6 & No & Excellent \\
\hline 7 & 7 & Female & Right & Traffic accident & 6 & 4 & No & Excellent \\
\hline 8 & 13 & Male & Left & Traffic accident & 5 & 5 & Pin tract infection & Excellent \\
\hline 9 & 6 & Female & Left & Other & 6 & 4 & No & Excellent \\
\hline 10 & 11 & Male & Right & Sprain & 4 & 3 & No & Excellent \\
\hline 11 & 8 & Male & Left & Sprain & 8 & 6 & No & Excellent \\
\hline 12 & 7 & Female & Right & Sprain & 7 & 5 & No & Excellent \\
\hline 13 & 4 & Female & Right & Other & 5 & 4 & No & Excellent \\
\hline 14 & 5 & Male & Left & Traffic accident & 6 & 4 & No & Excellent \\
\hline 15 & 14 & Male & Right & Traffic accident & 4 & 5 & No & Excellent \\
\hline 16 & 10 & Female & Left & Sprain & 4 & 7 & No & Good \\
\hline 17 & 8 & Female & Right & Sprain & 5 & 5 & No & Excellent \\
\hline 18 & 3 & Male & Left & Heavy objects & 7 & 5 & No & Excellent \\
\hline 19 & 7 & Female & Right & Sprain & 7 & 4 & No & Excellent \\
\hline 20 & 10 & Female & Right & Traffic accident & 8 & 6 & No & Excellent \\
\hline 21 & 9 & Male & Left & Sprain & 5 & 5 & No & Excellent \\
\hline 22 & 8 & Female & Right & Traffic accident & 7 & 7 & No & Excellent \\
\hline 23 & 7 & Male & Left & Sprain & 8 & 6 & No & Excellent \\
\hline
\end{tabular}

Table 3 Comparison of VAS score between preoperation and postoperation

\begin{tabular}{llll}
\hline $\begin{array}{l}\text { Preoperation } \\
(\boldsymbol{m} e a n+\text { SD) }\end{array}$ & $\begin{array}{l}\text { Postoperation } \\
(\boldsymbol{m} \text { ean } \pm \text { SD) }\end{array}$ & $\boldsymbol{t}$ value & $\boldsymbol{P}$ value \\
\hline $7.3 \pm 1.5$ & $3.1 \pm 1.4$ & 9.6 & $<0.05$ \\
\hline
\end{tabular}

external fixator combined with limited open reduction was used to treat in pediatric tibia fractures, and it found that the therapeutic effect was satisfactory [22]. Joystick technique refers to the use of metal bone pin into the fracture, followed by reaching the purpose of reduction. 

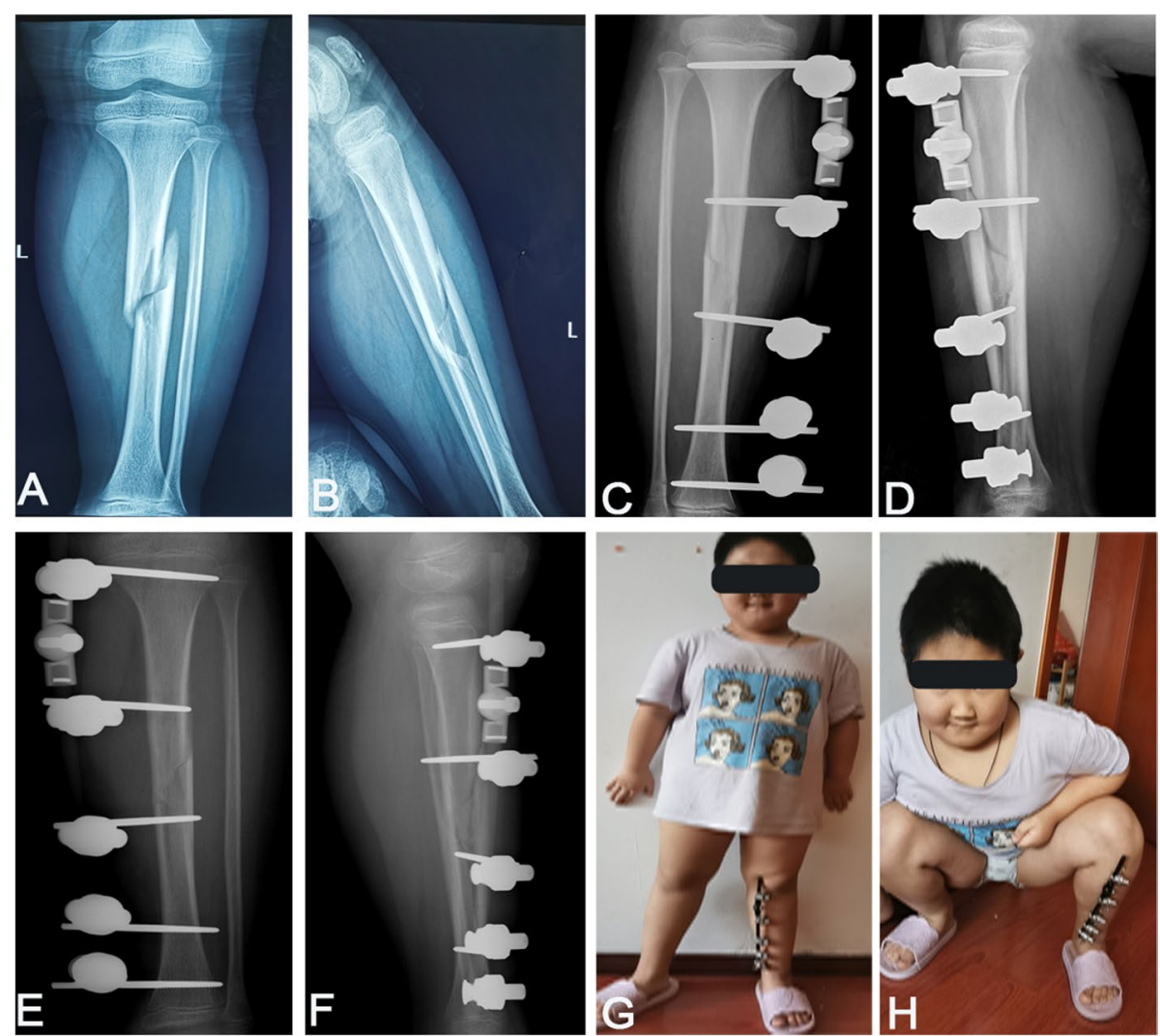

Fig. 3 Representative cases with tibia shaft fractures at preoperation and postoperation. A, B X-ray images of tibia shaft fractures of an 8-year-old boy. C, D X-ray images at postoperative immediate showed good reduction. E, F X-ray images at postoperative 1 month. G, H At 5 weeks postoperatively, the patient walked without crutches and recovered well

Since joystick technique can achieve closed reduction of fractures that originally required open reduction, it is becoming an emerging method in the management of fractures [23-25]. In the current study, unilateral external fixator combined with joystick for fracture reduction was used for pediatric tibia shaft fractures, which obtained benefit effects.

Average hospital duration in the current study was 5.9 days, which was lined with previous study using monolateral external fixation combined with open reduction [22]. In the aspects of weight-bearing, we found that the average time was keeping with the abovementioned previous study [22], however superior to TEN type of surgical treatment $[11,26]$. In our series, full fracture healing and no complications were observed in all patients, which differ from the outcomes using external fixation in the Gordon et al. [27] report. However, a recent study has used the hybrid external fixation by the joystick method in the bicondylar tibia plateau fractures, and then found the full fracture healing in all cases [28]. Importantly, certain matters should be paid attention during the surgery process, which may be closely associated with the therapeutic effect. Briefly, reduction of the local temperature during the drilling or half-insertion of the needle can effectively avoid osteonecrosis induced by excessive temperature. The sharpness of the drill is important as well. Additionally, ensuring that each half-pin was inserted into bicortex in our study, which has been proved in the previous study [29].

As we have known, the challenges faced in external fixation are mainly the fixation strength and pin-tract infection in the treatment of pediatric tibia shaft fractures [2]. Since external fixator cannot achieve the same nail density as the locking bone plate, how to obtain the maximum fixation strength under the premise of placing the limited number of screws is the key to the success of the treatment [15]. A previous study has used unilateral external fixators to treat the 29 children with tibia shaft fractures, of which 4 patients (13\%) experienced loss of reduction [27]. Additionally, a retrospective study conducted by Parameswaran et al. [30] has showed that $11.2 \%$ of external fixation patients had pin tract infection. Furthermore, previous studies have documented the soft-tissue trauma as a risk factor for 

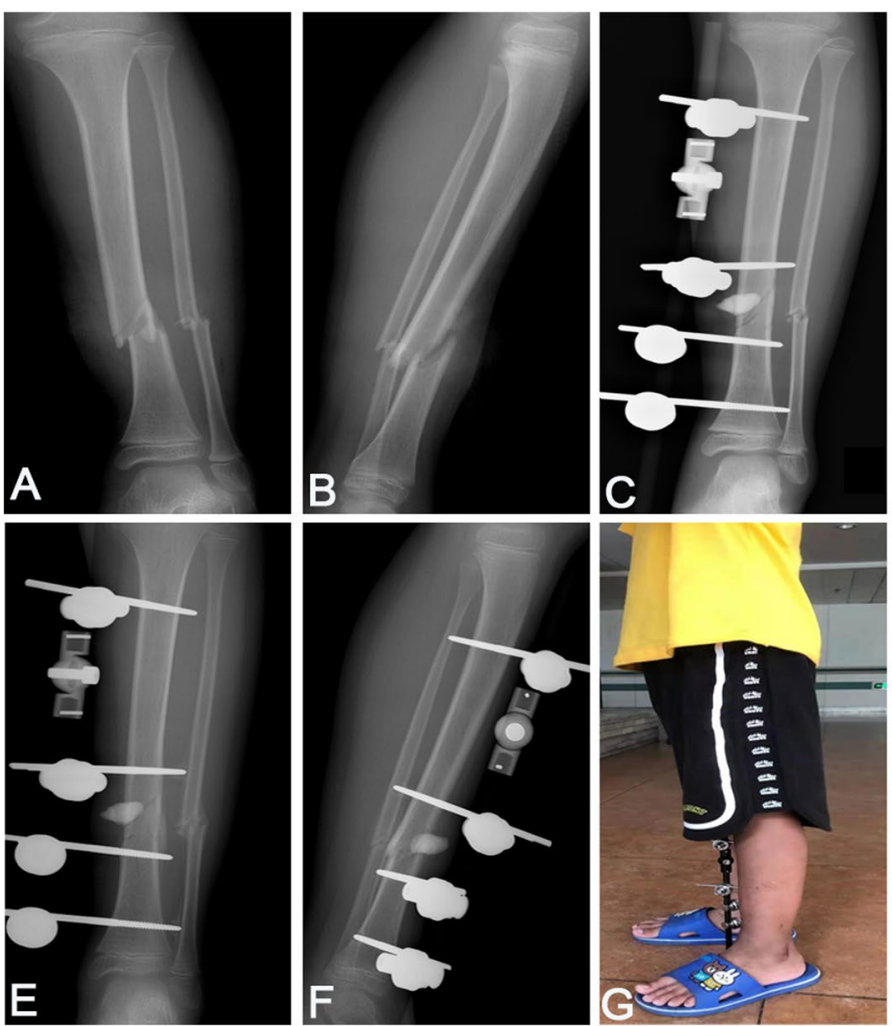
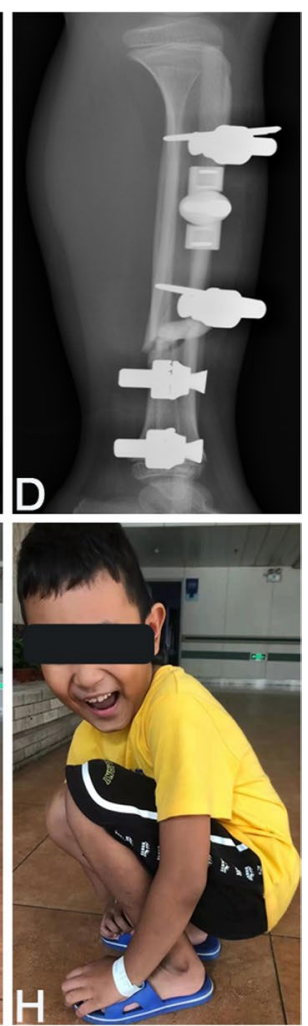

Fig. 4 Representative cases with Gustilo type I open tibia-fibula shaft fractures at preoperation and postoperation. A, B X-ray images of a 7-year-old boy at preoperation. $\mathbf{C}, \mathbf{D}$ X-ray images at postoperative immediate showed good reduction and use of local antibiotic bone cement to prevent infection. E, F X-ray images at postoperative 1 month. G, H At 4 weeks postoperatively, the patient walked without crutches and recovered well

Table 4 The advantages and limitations in the study

\begin{tabular}{ll}
\hline Advantages & Limitations \\
\hline A new technology attempt & Small sample \\
Minimal-invasive approach & Single arm retrospective study \\
Early recovery of lower limb function & Single center study \\
Simple operation & - \\
Avoiding second operation & - \\
\hline
\end{tabular}

infection rate [31, 32]. In the current study, a variety of methods were used to minimize the stimulation of the soft tissues. First, half-pins were inserted from the inner surface of the tibia perpendicular to the bone surface. Second, No. 11 (sharp blade) or No. 15 (gun blade) was used to pre-cut and then half-pins were inserted. In addition, since the fracture was displaced, the distal and proximal half-pins were firstly inserted to restore the relative position of the fracture and soft tissue, and then the half-pins were placed adjacent to the fracture. After following the standard nail placement technique and reasonable care, only 2 patients $(8.7 \%)$ had a slight pin-tract infection, who improved after oral antibiotics without causing fixation failure.

In children, fractures heal quickly, but new calluses are softer [33]. A previous study has revealed that weight-bearing may cause deformity or re-fracture in the lower limbs if the external fixation is completely removed after the fracture healing [2]. Additionally, Greene et al. [34] have found that local pressure stimulation can effectively promote bone formation and calcium accumulation, indicating gradually increasing the weight-bearing of the fracture site under the protection of external fixators may be an effective means to prevent re-fracture. In our study, the external fixation device is gradually removed for 2-3 times, when the patient recovered the function of the lower limbs and walked without crutches. Fortunately, none of the 23 patients in this study had fractures after removal of external fixation.

There were some limitations in the current study. Briefly, this study was single arm retrospective and conducted in a single center medical institution with a small sample. 


\section{Conclusions}

Unilateral external fixation combined with joystick for fracture reduction had advantages of simple operation, minimum trauma, early recovery of lower limb function, and no risk of complications. It may provide a new choice for children with tibia shaft fractures who require surgical treatment. However, a randomized controlled study will be conducted in the future to verify the efficacy.

\section{Abbreviations}

TEN: Titanium elastic nail; VAS: Visual analog scale.

\section{Acknowledgements}

Not applicable.

\section{Authors' contributions}

$\mathrm{TZ}, \mathrm{ZZ}$, and XHW conceived the study. TZ, XHW, BW, and YDL provided the materials and samples. XHW, BW, YDL, XZH, and ZZ contributed to the data collection, analysis and interpretation of the results, and writing of the manuscript. TZ and ZZ provided administrative support. All authors read and approved the final manuscript and consented to publish this manuscript.

\section{Funding}

The study was funded by "333 talents project" of Hebei province (A202101060) and scientific research fund of Hebei provincial health commission (20210120).

\section{Availability of data and materials}

All data generated or analyzed during this study are included in this article.

\section{Declarations}

\section{Ethics approval and consent to participate}

The study was approved by the ethical committee of The Third Hospital of Hebei Medical University (W2021-011-1), and all methods were carried out in accordance with relevant guidelines and regulations/Declaration of Helsinki. Informed consent obtained from their parents or legal guardian.

\section{Consent for publication}

Not applicable.

\section{Competing interests}

All authors declare no potential conflict of interest.

\section{Author details \\ 1Emergency, Trauma Center, The Third Hospital of Hebei Medical University, No.139 Ziqiang Road of Qiao'xi District, Shijiazhuang 050000, Hebei, China. ${ }^{2}$ Monitoring and Evaluation Office, Health Guidance Center of Hebei Provincial Health Commission, Shijiazhuang, China. ${ }^{3}$ Three Wards of Traumatology Orthopedics, The Third Hospital of Shijiazhuang City, Shijiazhuang, Hebei Province, China.}

Received: 18 May 2021 Accepted: 23 July 2021

Published online: 12 August 2021

\section{References}

1. Buckley SL, Smith G, Sponseller PD, Thompson JD, Griffin PP. Open fractures of the tibia in children. J Bone Joint Surg Am. 1990;72:1462-9.

2. Mashru RP, Herman MJ, Pizzutillo PD. Tibial shaft fractures in children and adolescents. J Am Acad Orthop Surg. 2005;13:345-52.

3. Hogue GD, Wilkins KE, Kim IS. Management of pediatric tibial shaft fractures. J Am Acad Orthop Surg. 2019;27:769-78.
4. Palmu SA, Auro S, Lohman M, Paukku RT, Peltonen لـ, Nietosvaara Y. Tibial fractures in children. A retrospective 27-year follow-up study. Acta Orthop. 2014:85:513-7.

5. Patel NK, Horstman J, Kuester V, Sambandam S, Mounasamy V. Pediatric tibial shaft fractures. Indian J Orthop. 2018:52:522-8.

6. Kleiner JE, Raducha JE, Cruz AI Jr. Increasing rates of surgical treatment for paediatric tibial shaft fractures: a national database study from between 2000 and 2012. J Child Orthop. 2019;13:213-9.

7. Cruz AI Jr, Raducha JE, Swarup I, Schachne JM, Fabricant PD. Evidencebased update on the surgical treatment of pediatric tibial shaft fractures. Curr Opin Pediatr. 2019;31:92-102.

8. Pennock AT, Bastrom TP, Upasani W. Elastic intramedullary nailing versus open reduction internal fixation of pediatric tibial shaft fractures. J Pediatr Orthop. 2017:37:e403-8.

9. Ligier JN, Metaizeau JP, Prévot J, Lascombes P. Elastic stable intramedullary nailing of femoral shaft fractures in children. J Bone Joint Surg Br. 1988;70:74-7

10. Zubair A, Samuelson EM, Morris RP, Foreman M, Gagnon-Bartsch JA, Rosenfeld SB. Quadruple versus double flexible intramedullary nails to treat pediatric distal-third tibial shaft fractures: a biomechanical comparison. J Pediatr Orthop. 2020;40:487-91.

11. Canavese F, Botnari A, Andreacchio A, Marengo L, Samba A, Dimeglio A, et al. Displaced tibial shaft fractures with intact fibula in children: nonoperative management versus operative treatment with elastic stable intramedullary nailing. J Pediatr Orthop. 2016;36:667-72.

12. El-Alfy B, Ali AM, Fawzy SI. Comminuted long bone fractures in children. Could combined fixation improve the results? J Pediatr Orthop B. 2016;25:478-83.

13. Beltsios M, Savvidou O, Kovanis J, Alexandropoulos P, Papagelopoulos P. External fixation as a primary and definitive treatment for tibial diaphyseal fractures. Strateg Trauma Limb Reconstr. 2009:4:81-7.

14. Mediouni M, Schlatterer DR, Madry H, Cucchiarini M, Rai B. A review of translational medicine. The future paradigm: how can we connect the orthopedic dots better? Curr Med Res Opin. 2018;34:1217-29.

15. Fragomen AT, Rozbruch SR. The mechanics of external fixation. Hss j. 2007;3:13-29.

16. Johner R, Wruhs $O$. Classification of tibial shaft fractures and correlation with results after rigid internal fixation. Clin Orthop Relat Res 1983;178:7-25

17 O'toole RV, Gary UL, Reider L, Bosse MJ, Gordon WT, Hutson J, et al. A prospective randomized trial to assess fixation strategies for severe open tibia fractures: modern ring external fixators versus internal fixation (FIXIT Study). J Orthop Trauma. 2017;31(Suppl 1):S10-7.

18. Garg S, Khanna V, Goyal MP, Joshi N. Unreamed intra-medullary nail versus half pin external fixator in grade III [A \& B] open tibia fractures. J Clin Orthop Trauma. 2019;10:941-8.

19. Alhammoud A, Maaz B, Alhaneedi GA, Alnouri M. External fixation for primary and definitive management of open long bone fractures: the Syrian war experience. Int Orthop. 2019:43:2661-70.

20. Bråten $M$, Helland $\mathrm{P}$, Grøntvedt T, Aamodt A, Benum P, Mølster A. External fixation versus locked intramedullary nailing in tibial shaft fractures: a prospective, randomised study of 78 patients. Arch Orthop Trauma Surg. 2005;125:21-6.

21. Clifford RP, Lyons TJ, Webb JK. Complications of external fixation of open fractures of the tibia. Injury. 1987;18:174-6.

22. Simon AL, Apostolou N, Vidal C, Ferrero E, Mazda K, Ilharreborde B. Paediatric tibial shaft fractures treated by open reduction and stabilization with monolateral external fixation. J Child Orthop. 2018:12:20-8.

23. Basaran SH, Ercin E, Bilgili MG, Bayrak A, Cumen H, Avkan MC. A new joystick technique for unsuccessful closed reduction of supracondylar humeral fractures: minimum trauma. Eur J Orthop Surg Traumatol. 2015:25:297-303

24. Wei YS, Liu WL, Bai R, Li DH, Zhao ZQ, Wang Y, et al. The use of a transolecranon pin joystick technique in the treatment of multidirectionally unstable supracondylar humeral fractures in children. J Pediatr Orthop B. 2020:29:452-7.

25. Liu F, Ju L, Tang K, Lou Y. The use of percutaneous joystick reduction and limited open reduction techniques in pediatric femoral shaft fractures: a study of 63 cases. J Pediatr Orthop B. 2016;25:375-80. 
26. Lardelli P, Frech-Dörfler M, Holland-Cunz S, Mayr J. Slow recovery of weight bearing after stabilization of long-bone fractures using elastic stable intramedullary nails in children. Medicine. 2016;95:e2966.

27. Gordon JE, Schoenecker PL, Oda JE, Ortman MR, Szymanski DA, Dobbs $\mathrm{MB}$, et al. A comparison of monolateral and circular external fixation of unstable diaphyseal tibial fractures in children. J Pediatr Orthop B. 2003;12:338-45.

28. Kuyucu E, Kara A, Say F, Erdil M, Bülbül M, Gülenç B. Application of hybrid external fixation by the "joystick method" in bicondylar tibial plateau fractures: technical note. Ulus Travma Acil Cerrahi Derg. 2018;24:263-7.

29. lobst CA. Hexapod external fixation of tibia fractures in children. J Pediatr Orthop. 2016;36(Suppl 1):S24-8.

30. Parameswaran AD, Roberts CS, Seligson D, Voor M. Pin tract infection with contemporary external fixation: how much of a problem? J Orthop Trauma. 2003;17:503-7.

31. Bachoura A, Guitton TG, Smith RM, Vrahas MS, Zurakowski D, Ring D. Infirmity and injury complexity are risk factors for surgical-site infection after operative fracture care. Clin Orthop Relat Res. 2011;469:2621-30.
32 Kälicke T, Schlegel U, Printzen G, Schneider E, Muhr G, Arens S. Influence of a standardized closed soft tissue trauma on resistance to local infection. An experimental study in rats. J Orthop Res. 2003;21:373-8.

33. Omeroğlu H. Basic principles of fracture treatment in children. Eklem Hastalik Cerrahisi. 2018:29:52-7.

34 Greene DA, Naughton GA, Briody JN, Kemp A, Woodhead H, Corrigan L. Bone strength index in adolescent girls: does physical activity make a difference? Br J Sports Med. 2005;39:622-7 discussion 7.

\section{Publisher's Note}

Springer Nature remains neutral with regard to jurisdictional claims in published maps and institutional affiliations.
Ready to submit your research? Choose BMC and benefit from:

- fast, convenient online submission

- thorough peer review by experienced researchers in your field

- rapid publication on acceptance

- support for research data, including large and complex data types

- gold Open Access which fosters wider collaboration and increased citations

- maximum visibility for your research: over 100M website views per year

At BMC, research is always in progress.

Learn more biomedcentral.com/submissions 